\title{
Livros e leitura para o povo: ascensão e decadência da Bibliotecas Populares no Império Brasileiro, 1870 - 1889
}

\author{
Doi: $10.25100 /$ hye.v14i51.7275
}

Artículo recibido: 12-2018 | Artículo aceptado: 12-2018

\section{Nelson Schapochnik}

Profesor Universidad de São Paulo (USP), São Paulo, Brasil.

Correo electrónico: nschapo@uol.com.br

Forma de citar este artículo: Schapochnik, Nelson. "Livros e leitura para o povo: ascensão e decadência da Bibliotecas Populares no Império Brasileiro, 1870 - 1889”. Historia y Espacio, vol. 14, n 51 (2018): 199-229. Doi: 10.25100/hyev14i51.7275.

Artículo Tipo 1: de investigación. 


\section{Livros e leitura para o povo: ascensão e decadência da Bibliotecas Populares no Império Brasileiro, 1870 - 1889}

Resumo: Este ensaio apresenta os resultados parciais da investigação sobre uma modalidade peculiar de biblioteca implantada em distintas províncias do império brasileiro entre os anos 70 e 80 do século XIX: as bibliotecas populares. Apresentando uma lógica e estratégia distinta de outros modelos biblioteconômicos, sua emergência esteve pautada em ações que mesclavam o paternalismo das elites e aquele traço denominado por Armando Petrucci de "filantropia do saber". Não raro, sua ascensão esteve articulada com a atuação dos clubes republicanos e abolicionistas, tendo se verificado também sua difusão por meio de lojas maçônicas. Com base em uma documentação variada (discursos de fundacionais e celebrativos, relatórios e artigos publicados na imprensa) procuro traçar uma cartografia destas bases institucionais da leitura, explorar os discursos prescritivos sobre os objetivos e destinatários, compreender a sua organização interna e funcionamento. Por fim, exploro as tensões entre o projeto laico de proporcionar às classes populares o acesso à cultura impressa, sobretudo do livro didático e formativo, a crença na função moralizante da leitura, e as práticas efetivas destes leitores que demonstravam uma predileção pelo gênero romance.

Palavras chave: Bibliotecas Populares, Instrução, Livros, Leitura.

\section{Libros y lectura para el pueblo: ascenso y decadencia de las Bibliotecas \\ Populares en el Imperio Brasileño (1870 - 1889)}

Resumen: Este ensayo presenta los resultados parciales de la investigación sobre una modalidad peculiar de biblioteca implantada en distintas provincias del imperio brasileño entre los años 70 y 80 del siglo XIX: las bibliotecas populares. Con una lógica y estrategia distinta de otros modelos biblioteconómicos, su emergencia estuvo pautada en acciones que mezclaban el paternalismo de las élites y ese rasgo denominado por Armando Petrucci de "filantropía del saber". No es raro, su ascensión estuvo articulada con la actuación de los clubes republicanos y abolicionistas, habiéndose comprobado también su difusión por medio de tiendas masónicas. Con base en una documentación variada (discursos fundacionales y celebrativos, informes y artículos publicados en la prensa) procuro trazar una cartografía de estas bases institucionales de la lectura, explorar los discursos prescriptivos sobre los objetivos y destinatarios, comprender su organización interna y funcionamiento. Por último, explico las tensiones entre el proyecto laico de proporcionar a las clases populares el acceso a la cultura impresa, sobre todo del libro didáctico y formativo, la creencia en la función moralizante de la lectura, y las prácticas efectivas de estos lectores que demostraban una predilección por el género novela.

Palabras clave: Bibliotecas populares, Instrución, Libros, Lectura. 


\section{Books and reading for the people: rise and decay of the Popular Libraries in the Brazilian Empire (1870 - 1889)}

Abstract: This essay presents the partial results of the research on a peculiar modality of library implanted in different provinces of the Brazilian empire between the years 70 and 80 of the nineteenth century: the popular libraries. Presenting a logic and strategy distinct from other library models, its emergence was based on actions that blended the paternalism of the elites and that trait called by "Petrucci" of "philanthropy of knowledge". Not infrequently, its rise was articulated with the action of the republican and abolitionist clubs, having also been diffused by means of Masonic lodges. Based on a variety of documentation (foundational and celebratory speeches, reports and articles published in the press), I draw a map of these institutional bases of reading, explore the prescriptive discourses on the objectives and recipients, understand their internal organization and functioning. Finally, I explore the tensions between the lay project of providing the popular classes with access to print culture, especially the textbook and formative book, belief in the moralizing function of reading, and the effective practices of these readers who displayed a predilection for the novel genre.

Keywords: Public Libraries, Instruction, Books, Reading. 



\section{Nelson Schapochnik \\ Livros e leitura para o povo: ascensão e decadência da Bibliotecas Populares no Império Brasileiro, 1870 - 1889}

Ao folhear diferentes diários publicados pela imprensa brasileira oitocentista no início dos anos 70, é possível acompanhar algumas discussões e tomar contato com eventos que tiveram ampla repercussão naquele momento. Talvez a notícia mais comentada tenha sido o armistício com o Paraguai após uma guerra que perdurou por cerca de cinco anos. Todavia, no front interno, outras batalhas também foram objeto de debates e de divulgação nos periódicos, a saber: a ascensão do movimento republicano, a questão do abolicionismo e os resultados do primeiro recenseamento. Respectivamente, eles representavam uma crítica ao regime monárquico e a busca de um novo sistema de governo amparado por bases políticas e ideológicas anunciadas na Convenção Republicana (1870), a emergência de fraturas na ordem senhorial com a promulgação da lei do Ventre-Livre que embora paliativa, concedia liberdade aos escravos nascidos a partir de $1871 \mathrm{e}$, por fim, a explicitação de certas mazelas da sociedade brasileira referendadas pelo recenseamento com amplo destaque para as deficiências da instrução pública e o expressivo analfabetismo.

Muito embora o acesso ao letramento não constituísse exigência formal para o exercício da cidadania, uma vez que o voto era censitário, isto é, baseado na riqueza, o expressivo número de analfabetos configurava-se como um empecilho à mudança sendo também identificado como um traço limitador para a consolidação da opinião pública. É o que se pode apreender na crônica de Machado de Assis publicada na Semana Ilustrada: 
(...) publicou-se há dias o recenseamento do Império, do qual se colige que $70 \%$ da nossa população não saber ler.

Gosto dos algarismos, porque não são de meias medidas, nem de metáforas. Eles dizem as coisas pelo seu nome, às vezes um nome feio, mas não havendo outro, não o escolhem. São sinceros, francos, ingênuos. As letras fizeram-se para frases; $\mathrm{o}$ algarismo não tem frases, nem retórica.(...) A Nação não sabe ler. Há só 30\% dos indivíduos residentes neste país que podem ler; desses uns $9 \%$ não leem letra de mão. $70 \%$ jazem na mais profunda ignorância. (...) $70 \%$ dos cidadãos votam do mesmo modo que respiram: sem saber porque nem o quê. Votam como vão à festa da Penha - por divertimento. A Constituição é para eles uma coisa inteiramente desconhecida. Estão prontos para tudo: uma revolução ou um golpe de Estado.

(...) As instituições existem, mas por e para 30\% dos cidadãos. Proponho uma reforma no estilo político. Não se deve dizer: 'consultar a nação, representantes da nação, os poderes da nação'; mas 'consultar os 30\%, representantes dos $30 \%$, poderes dos $30 \%$ '. A opinião pública é uma metáfora sem base; há só a opinião dos $30 \%{ }^{1}$

Objeto de críticas pelas suas muitas lacunas, o recenseamento de 1872 significou entre outras coisas o ingresso da administração pública numa era estatística que, bem ou mal, passaria a determinar ou potencializar ações públicas concretas do governo imperial e do governo das províncias no campo da educação ${ }^{2}$. Daí a ênfase do cronista no poder da mensuração e de que maneira o emprego deste procedimento desnudava a falácia da eloquência parlamentar. Era necessário reconhecer que metáfora alguma poderia denegar os números fornecidos pela pesquisa: um imenso contingente populacional estava mergulhado "na mais profunda ignorância". Do ponto de vista de um homem de letras, o acesso rarefeito ao letramento era visto como um entrave para a expansão das práticas da leitura, o que também se constituía em um obstáculo para a concretização do desejo de viver de sua própria pena. Daí a observação de um confrade de letras que afirmava que no Brasil não havia

1 Machado de Assis. "História de Quinze Dias (15/08/1876)”. En: Obra Completa v.III. (Rio de Janeiro: Nova Aguillar, 1986) 344-345.

2 A percepção da precariedade da instrução elementar e do desinteresse do Governo Geral na unificação do sistema de ensino foi alvo de vários projetos e relatórios apresentados no parlamento. Sobre o tema da instrução popular no período, veja: Alessandra Frota Martinez. Educar e Instruir: A Instrução Popular na Corte - 1870 a 1889 (Niterói: Universidade Federal Fluminense, 1997); Luciano Mendes Faria Filho. "Educação do povo e autoritarismo das elites: instrução pública e cultura política no século XIX”. Dimensões. Vitória, v.13 (2001): 75-83. 
outra saída para a sobrevivência de um candidato à carreira literária que não fosse a burocracia ou o jornalismo ${ }^{3}$.

A divulgação dos dados do recenseamento revelava que o analfabetismo e o acesso às primeiras letras se espraiavam de maneira heterogênea entre a população brasileira. Os indicadores atestavam que no plano espacial as carências da zona rural suplantavam as das vilas e cidades. A sua distribuição social era marcadamente excludente no que dizia respeito à população escrava. Da mesma maneira, atingia com maior vigor a população mais velha e se mostrava ainda desigual sob o critério do gênero. Sob o título "Escolas! Escolas! Escolas!”, o jornal humorístico O Mosquito abordava esta última assimetria nos seguintes termos:

Há apenas entre 10.108.291 habitantes, 550.981 mulheres que saibam ler. Os pais das nossas compatriotas não hão de ter muito trabalho, para que suas filhas não escrevam aos namorados!

As Stäel e as George Sand não hão de abundar, com certeza, num país onde vão à escola apenas 165.098 meninas por 795.574 que ficam em casa a conversar na cozinha com a crioula! ${ }^{4}$

Ao mesmo tempo em que a imprensa noticiava debilidades de natureza variada que afligiam a sociedade brasileira, ela também funcionava como uma caixa de ressonância dos debates e projetos que eram travados no Parlamento, nas Assembleias Legislativas e Câmaras Municipais. Mas não só, difundiam discursos prescritivos que expressavam fórmulas e empreendimentos postulados por setores do clero, de profissionais e de associações voluntárias empenhadas em fazer avançar a "magna causa da educação". Dentre os dispositivos mobilizados por estes variados grupos, as bibliotecas populares apareciam como a panaceia para reverter as trevas da ignorância e promover, simultaneamente, a fé nos livros e no conhecimento para o povo, num verdadeiro programa de regeneração moral da população ${ }^{5}$.

3 Quintino Bocayuva. Estudos criticos e literários (Rio de Janeiro: Typographia Nacional, 1858) 3 .

4 O Mosquito (RJ), 10/08/1876, nº 378, 3.

5 Entre os estudos sobre as bibliotecas populares destaco: Grahan Keith Barnett. Histoire des bibliothèques publiques en France de la Révolution à 1939 (Paris: Cercle de la Librairie/ Promodis, 1987); Noë Richter. La lecture et ses instituitions, 1700-1918. v.2. (Bassac: Ed. Plein Chant et Université du Maine, 1987); Anne-Marie Chartier e Jean Hébrard. Discours sur la lecture (1880-1980) (Paris: Centre Georges Pompidou, 1989); Antonio Viñao Frago. 
Sob a forma de discursos prospectivos e muitas vezes messiânicos, a biblioteca popular passou a ser uma tópica recorrente nos discursos políticos, nas celebrações cívicas, nos informes jornalísticos, como também nas cartas de leitores remetidas aos diversos periódicos. Não raro, esta referência se via mesclada a categorias como "ilustração", "progresso", "patriotismo", "civilização" e a "Santa Religião Católica Apostólica Romana”. Apesar da incompatibilidade entre os termos reunidos, a bricolagem parece ter surtido efeito. A biblioteca popular passou a figurar como a tradução do desejo dos grupos dirigentes de sintonizarem a tarefa de aculturação das classes populares por meio do texto impresso, enquanto uma experiência similar àquelas produzidas em países que poderiam servir de paradigma civilizacional, como a França, a Alemanha e os Estados Unidos. De acordo com Armando Petrucci, este fenômeno se enquadrava no conjunto de práticas que ele denominou de "filantropia do saber", ao enfatizar o processo de difusão do conhecimento para as classes populares. Por sua vez, Angela Alonso, ao estudar a emergência de associações voluntárias ligadas à causa da abolicionista, denominou este tipo de ação de "elitismo benevolente"

Por vias oblíquas, uma vez que os apelos para fundamentar a implantação das bibliotecas populares foi encaminhado por interesses e orientações políticas, culturais e religiosas diversas, constatou-se uma verdadeira mobilização em diferentes pontos do império brasileiro a favor desta instituição. De maneira

“A cultura por la lectura. Las Bibliotecas populares (1869-1885)”. En: Clases populares, cultura, educación, siglos XIX-XX, editado por Jean-Louis Guereña y Alejandro Tina (Madrid: Casa de Velázquez/UNED, 1989); Noë Richter. "Les bibliothèques populares et la lecture ouvrière”. En: Histoire des bibliothèques françaises. v.3, dirigido por Dominique Varry (Paris: Cercle de la Librairie/Promodis, 1991); Luis García Ejarque. Historia de la lectura pública em España (Gijón: Trea, 2000); Carlos Alberto Rebelo. A difusão da leitura pública: As bibliotecas populares (1870-1910) (Porto: Campo das Letras, 2002); Nicolás Quiroga. “Lectura y política. Los lectores de la Biblioteca Popular Juventud Moderna de Mar del Plata (fines de los años treinta y principio de los cuarenta)". Anuario IEHS, n⿳018 (2003): 449-474; Thomas Augst and Kenneth Carpenter (ed.s). Institutions of Reading: The social life of Libraries in the United States (Amherst and Boston: University of Massachusetts Press, 2007); Javier Planas. Libros, lectores y sociabilidades de lecturas: Una historia de los orígenes de las bibliotecas populares en la Argentina (Buenos Aires: Ampersand, 2017); Maria de Fátima Machado Martins Pinto. Bibliotecas Populares em Portugal: Práticas e representações, esboçar uma missão (1870-1930). Lisboa: Instituto de Educação/Universidade de Lisboa, 2017 (Tese de doutorado).

6 Respectivamente: Armando Petrucci. “Bibliotecas y lectura: entre progresso y conservación”. Em: Alfabetismo, escritura, sociedade (Barcelona: Gedisa, 1999) 280-289; Angela Alonso. "Associativismo avant la lettre - as sociedades pela abolição da escravidão no Brasil oitocentista”. Sociologias ano 13, nº28, set./dez (2011): 166-199. 
concisa, aglutinando as distintas formas de investimento e expectativas que se atribuíam aos "cruzados da civilização”, o Dr. Antonio Serrano Gonçalves de Andrade, juiz do município de Assú, afirmava: "Quem diz Biblioteca Popular diz ensino popular, educação do povo” ${ }^{\text {. }}$

Com base em um repertório de textos de natureza variega (discursos fundacionais, efemérides, celebrações, notas sobre doações e/ou envio de livros) publicados na imprensa brasileira no período de 1870 - 1889, foi possível registrar a instalação de 69 bases institucionais de leitura que se intitulavam Bibliotecas Populares, incluindo também algumas associações cujos fins previam a criação de bibliotecas desta natureza. $\mathrm{O}$ gráfico abaixo indica a cronologia da instalação destas bibliotecas (Figura 1).

Figura 1. Cronologia da instalação de Bibliotecas Populares no Império brasileiro (1870-1889)

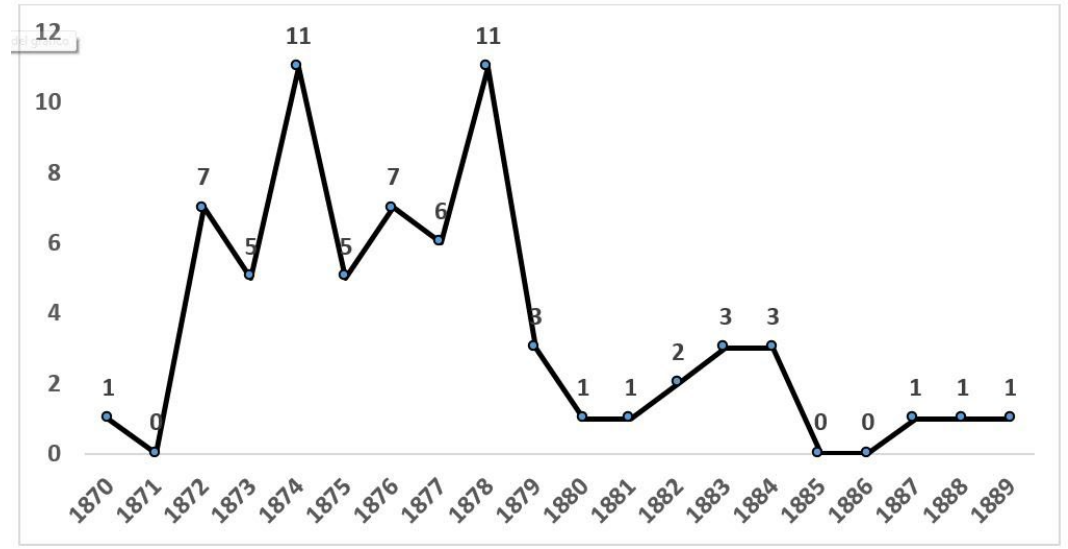

Fuente: elaboración propia.

Como é possível constatar, o primeiro decênio expressa um movimento ascensional, atestando a adesão ao programa de fornecer livros e instrução por meio das bibliotecas populares. O total de instituições implementadas neste intervalo remonta a 56 bibliotecas, correspondendo a $81 \%$ do conjunto delas. Já, no segundo decênio, a tendência se inverteu, denotando um refluxo, que incidiu na instalação de apenas 13 bibliotecas, perfazendo 19\% do total.

O quadro seguinte tem por intuito agregar informações sobre a distribuição espacial das bibliotecas, permitindo assim traçar uma cartografia destas instituições. Sob esta perspectiva é possível vislumbrar uma geografia cultural que contribui para a compreensão deste fenômeno (Figura 2).

7 Correio do Assú (Assú, RN), 26/09/1874, 3. 
Figura 2. Instalação de Bibliotecas Populares nos municípios

\begin{tabular}{|c|c|c|}
\hline Ano & $\begin{array}{c}\text { № de } \\
\text { Bibliotecas }\end{array}$ & Localidade \\
\hline 1870 & 1 & Ponta Grossa (PR) \\
\hline 1872 & 7 & $\begin{array}{l}\text { São Luís (MA); Campanha (MG); Paranaguá (PR); Rio de } \\
\text { Janeiro, Vassouras, Petrópolis (RJ); Sorocaba (SP) }\end{array}$ \\
\hline 1873 & 5 & $\begin{array}{l}\text { Ponte Nova (MG); Barra Mansa, Campos, Itaboraí (RJ); } \\
\text { Amparo (SP) }\end{array}$ \\
\hline 1874 & 11 & $\begin{array}{c}\text { Pilar (AL); Valença (BA); Diamantina, Ubá (MG); Porto de } \\
\text { Cima (PR); Mossoró, Assú, São José do Mipibú (RN); Cunha, } \\
\text { Taubaté (SP) }\end{array}$ \\
\hline 1875 & 5 & $\begin{array}{c}\text { Penedo (AL); Teresina (PI); Castro (PR); Cantagalo (RJ); } \\
\text { Laguna (SC) }\end{array}$ \\
\hline 1876 & 7 & $\begin{array}{c}\text { Limeira de Itabapoana (ES); Cantagalo, Macaé, Magé, Nova } \\
\text { Friburgo, Parati (RJ); Itapetininga (SP) }\end{array}$ \\
\hline 1877 & 6 & $\begin{array}{c}\text { Tamanduá (MG); Santarém, Cametá, Vigia, Óbidos (PA); } \\
\text { São Paulo (SP) }\end{array}$ \\
\hline 1878 & 11 & $\begin{array}{l}\text { São Luís (MA); Recife (3), Olinda, Goiana, Vitória, } \\
\text { Gameleira, Jaboatão, Barreiros, Timbaúba (PE) }\end{array}$ \\
\hline 1879 & 3 & Aracati (CE); Monteiro, Recife (PE) \\
\hline 1880 & 1 & São José (SC) \\
\hline 1881 & 1 & Pomba (MG) \\
\hline 1882 & 2 & São João Nepomuceno (MG); Bragança Paulista (SP) \\
\hline 1883 & 3 & Nazaré (BA); Pesqueira (PE); Angra dos Reis (RJ) \\
\hline 1884 & 3 & $\begin{array}{l}\text { Paraíba do Norte (PB); Rezende (RJ); São Carlos do Pinhal } \\
\text { (SP) }\end{array}$ \\
\hline 1887 & 1 & Limeira (SP) \\
\hline 1888 & 1 & Jundiaí (SP) \\
\hline 1889 & 1 & Pelotas (RS) \\
\hline
\end{tabular}

Fuente: elaboración propia

Embora tenha se espraiado por diversas regiões do país, o quadro permite constatar que o processo de implantação de bibliotecas populares no Império não atingiu a totalidade das províncias, como foi o caso do Amazonas, Goiás, Mato-Grosso e Sergipe. Por sua vez, a distribuição espacial revela-se bastante heterogênea, indicando que algumas províncias obtiveram maior êxito na concretização do projeto. Neste caso, as províncias do Rio de Janeiro, de Pernambuco, de São Paulo e de Minas Gerais (respectivamente com 14, 13, 10 e 7 equipamentos), concentraram $64 \%$ do total, enquanto o conjunto das demais províncias apresentaram uma cifra bem inferior, remontando o total de 
$36 \%$. Ademais, o quadro contribui para a percepção de que este processo atingiu com mais vigor as cidades do interior (exibindo um total de 59 instituições), quando confrontado com as 10 bibliotecas populares instaladas nas capitais provinciais (São Luís, Rio de Janeiro, Teresina, São Paulo, Paraíba do Norte e Recife).

De certa forma, a disparidade reiterava a busca de alternativas para suprir a carência do acesso aos livros e satisfazer as demandas da instrução popular naquelas cidades que experimentavam condições materiais distintas daquelas oferecidas aos habitantes das capitais provinciais. Vale a pena recordar, que bem ou mal, os centros administrativos contavam com a presença de uma pluralidade de bases institucionais de leitura sob a forma de bibliotecas públicas, bibliotecas liceais, além de gabinetes de leitura e bibliotecas por subscrição mantidas por associações voluntárias e comunidades estrangeiras. ${ }^{8}$

Para além da geografia cultural que marcou este processo, ou ainda, do amplo espectro de fundamentos mobilizados pelos seus protagonistas, os discursos fundacionais e celebrativos são unânimes em reconhecer a experiência norteamericana, empreendida por Benjamin Franklin, como um modelo a ser seguido. As menções se multiplicam nas páginas da imprensa brasileira e serviam de estímulo para novos empreendimentos e de amparo para as experiências em curso. O trabalho da citação aqui empregados tinham uma função genealógica, estabeleciam uma filiação, inventavam uma boa tradição a ser replicada e dignificavam aqueles que empregavam a remissão à experiência promovida por Benjamin Franklin. Obviamente, o seu emprego anulava a especificidade dos contextos históricos onde emergiram estas experiências, mas ainda assim, ela denotava a circulação de ideias e de modelos, e a sua apropriação pelos protagonistas brasileiros. Da mesma forma, excertos do poema "O livro e a América”, do poeta abolicionista Castro Alves, são empregados nas falas e circulares sobre as bibliotecas, sobretudo os versos: "Oh! Bendito que semeia/ Livros...livros à mão cheia.../ E manda o povo pensar!" ${ }^{9}$. Aqui, fica a dúvida sobre o poder da citação, isto é, se ela efetivamente denotava o compromisso

8 Cf. N. Schapochnik. "A leitura no espaço e o espaço da leitura”. Cultura letrada no Brasil: objetos e práticas, organizado por Márcia Abreu e Nelson Schapochnik (Campinas/São Paulo: Mercado de Letras/FAPESP, 2005) 229-243.

9 O poema integra a obra Espumas Flutuantes, (1870). Cf. Castro Alves. Obra Completa (Rio de Janeiro: Nova Aguilar, 1976) 76-78. Sobre as práticas, forma e função das citações, a referência é Antoine Compagnon. O trabalho da citação (Belo Horizonte: Ed.UFMG, 1996) especialmente 45-47. 
dos letrados com as questões sociais ou, se simplesmente funcionava como um ornamento discursivo.

De acordo com a carta dirigida ao Ministro do Império, autoridade responsável entre outras funções pela gestão da Biblioteca Imperial e dos cursos superiores, e publicada com destaque na imprensa carioca, a implantação das bibliotecas populares era uma maneira de empregar a instrução pela leitura como estratégia de tutela. Esta solução atendia tanto a intenção de fornecer o acesso ao livro formativo e de promover o conhecimento útil, como também satisfazia o paternalismo das elites, seja na forma da caridade cristã, seja na modalidade da filantropia laica. De acordo com o bacharel Moreira Pinto, a situação experimentada na corte imperial era a seguinte:

Entre nós não há Bibliotecas populares, e das públicas e particulares contam-se apenas a Biblioteca Fluminense, que exige um quantitativo de quem quiser ler; o Gabinete Português que é privativo dos portugueses, e a Biblioteca Nacional que, apesar de mal situada, está aberta das 9 horas da manhã até as 2 da tarde, horas em que todos os indivíduos estão ocupados em seus trabalhos e não podem frequentá-la.

O homem que não tiver recursos no nosso país não pode ler.

Os livros são vendidos por preços somente ao alcance dos homens abastados.

Ninguém conhece a necessidade e utilidade de tal instituição, o seu efeito sobre a moral e os bons costumes. (...) A Biblioteca Popular é uma segunda escola, o livro é a razão, é a necessidade e muitas vezes a regeneração completa do homem viciado.

Ensinar o homem a ler e depois não se lhe dar o que ler, é o mesmo (...) como ter conseguido penetrar num pomar verdejante povoado das árvores mais úteis, e não colher nenhum dos multiplicados frutos que estejam convidando com as vantagens dos seus resultados medicinais, ou com as delícias de seu agradável sabor. ${ }^{10}$

O cenário traçado por Moreira Pinto apontava para uma série de agravantes que limitavam a difusão das práticas de leitura entre os setores menos favorecidos da população brasileira. Sem dúvida, o acesso aos livros era um deles. Além da tenuidade material que caracterizou a produção livreira no Brasil, marcada pela rarefação de insumos nacionais (fábricas de tipos e tintas) e da necessidade de importação de papel, o setor ainda se via diante

10 "Carta ao Sr. Ministro do Império - Bibliothecas Populares". Diário de Notícias (RJ), $02 / 03 / 1872,2$. 
de uma concorrência direta com o livro português. Importa acrescentar que a legislação fiscal estabelecia taxas mais elevadas para a importação de papel para impressão e para a encadernação, que aquelas aplicadas ao livro importado. $\mathrm{O}$ resultado desta operação não era nada interessante para os agentes da produção de impressos nacionais. Mesmo adicionando o custo de seguro e do frete, os artefatos procedentes do estrangeiro obtinham preços mais paupáveis do que os seus similares produzidos no Brasi ${ }^{11}$. Obviamente, os efeitos desta política econômica repercutiram diretamente na formação dos acervos das bibliotecas privadas e públicas. Portanto, reiterar os esforços pela criação e difusão das bibliotecas populares expressava a convicção de que elas seriam uma estratégia para suplantar a questão do acesso aos impressos, como simultaneamente, satisfazer os imperativos da instrução por meio de um corpus controlado, de caráter edificante e moralizador.

Corroborando o argumento favorável à instalação de bibliotecas populares, o periódico O Movimento (RJ) publicou um longo artigo em que apontava para as relações indissociáveis entre este equipamento cultural e o imperativo civilizacional assentado na instrução das classes populares. Os argumentos enfatizavam a morosidade das iniciativas oficias em contraposição a agilidade dos membros das comunidades locais. De acordo com o articulista, enquanto os legisladores gastavam inúmeras sessões para deliberar alguma medida de interesse popular, que nem sempre se concretizavam, as ações promovidas por comerciantes, professores, funcionários públicos e muitos "cidadãos notáveis" foram de fundamental importância para a obtenção de doações em dinheiro e de livros, revertidos na criação de associações e clubes mantenedores de bibliotecas populares. Ainda de acordo com o artigo, o programa destas instituições era totalmente distinto de outros modelos biblioteconômicos que "aspiravam a formação de sábios e doutos". Por isto mesmo, o repertório bibliográfico desejável deveria ser constituído por "folhetos, opúsculos, manuais, compêndios que entendem com a mecânica, com a química aplicada à indústria, com a economia política, enfim com as ideias que possam adiantar e desenvolver a inteligência das classes populares, que em geral aplicam-se aos trabalhos rurais ou às artes liberais"12.

Cumpre destacar que quaisquer que fossem as intenções que presidiram a concretização do projeto, as bibliotecas populares eram em tese um dispositivo

11 Laurence Hallewell. O livro no Brasil. 2. ed. revista e ampliada (São Paulo: Edusp, 2005) $222-223$

${ }^{12}$ O Movimento (RJ), 28/07/1872, 1 . 
de controle. Os livros foram outorgados a indivíduos que em razão de sua vulnerabilidade, de sua diferença cultural, de não saber ler bem, ou escolher seus livros, ficavam à mercê das diretrizes e competências do poder de intervenção, seja ele do poder municipal, concebido como o gestor dos bens públicos, ou das iniciativas desenvolvidas por pessoas eminentes, desejosas de deixar a marca de suas ideias na ordem social. Desta maneira, a biblioteca seria também olugar do recalque, ela reuniria aquilo que supostamente o povo não tem e até mesmo as formas de "apropriação concreta do livro, real ou simbólica (conservação para releitura, rabiscos, anotações, etc) eram proibidas a quem o tomava emprestado e podia ser mesmo objeto de uma sanção" ${ }^{13}$. Ao territorializar a leitura, seus gestores também introduziram protocolos que afetavam não apenas a dimensão performativa desta prática, mas também aquilo que se dava a ler. No primeiro caso, isto significava a necessidade de introjetar uma disciplina muitas vezes desconhecida pelos frequentadores da biblioteca, a saber: a introdução da lei do silêncio, a mediação de um funcionário com funções de bibliotecário, uma disposição corpórea, o emprego de um código de vestimenta, etc ${ }^{14}$. No segundo caso, o controle aparecia sob a forma de uma seleção ou filtro sobre o acervo recebido por meio de doações ou adquirido com verbas oriundas de subscrições ou repasse de recursos públicos.

É evidente que ao designar esta nova base institucional de leitura de "popular", procurava-se fixar um perfil aos destinatários ou usuários de acordo com as representações de seus fundadores. O povo e, por extensão, o popular assumia uma identidade complexa. A formulação era aplicada para distinguir uma determinada categoria social ou atividade profissional como, por exemplo, aquela que se verifica no discurso do presidente da província do Paraná que atribuía às bibliotecas populares o papel de "fornecer ao agricultor, ao operário, ao professor, a todas as classes livros instrutivos, que elevem o nível intelectual de cada uma delas"15.

Outra representação do povo e do popular forjada no discurso sobre a implantação desta modalidade de biblioteca é aquela que ao invés de apelar

13 Anne-Marie Chartier e Jean Hébrad, “Discours sur la lecture”, 118. A percepção do espaço da biblioteca como algo regido pela lei do recalque também foi explorada por Roland Barthes. Da leitura. O rumor da língua (São Paulo: Brasiliense, 1988) 46-47.

${ }^{14}$ Cláudio Denipote. "Decência imperial, silêncio republicano: normas e gestualidades da leitura em regimentos e estatutos de bibliotecas (1821-1918)”. Varia História v. 23 no38 (2007) 597-614.

15 Adolpho Lamenha Lins. Relatorio apresentado á Assembléa Legislativa do Paraná no dia 15 de fevereiro de 1877 pelo presidente da provincia (Curityba: Typ. da Viuva Lopes, 1877) 64. 
para qualquer traço classista, designa-os por uma via negativa ou por meio de categorias que denotam ausências ("boas doutrinas", "higiene”, "ignorância”, "costumes") que seriam suplantados pela ação edificante dos afortunados e esclarecidos. É sob o signo de uma argumentação evidentemente maniqueísta que os livros e a leitura serão mobilizados no sentido de promover a reforma social. Esta perspectiva pode ser observada no projeto de biblioteca popular implantada na cidade do Crato (CE), em 1870, pelo Pe. Antonio de Maria Ibiapina, cujo propósito era promover a instrução popular aliada aos valores do Catolicismo, "e assim ajudar a evitar os vícios, a violência, a ociosidade" ${ }^{16} \mathrm{da}$ população sertaneja masculina. Como também se faz presente na versão laica preconizada por um grupo de simpatizantes do positivismo e do evolucionismo, que encabeçou a implantação da biblioteca popular no município de Pesqueira (PE), no ano de 1883. De acordo com o professor e orador da instituição:

A criação de bibliotecas por todas as cidades do interior do Império não é, como alguns pensam, uma bibliomania, ou um objeto de luxo, nem de ostentação; sua utilidade é de primeira intuição, reconhecida por todos que se compenetram da necessidade de ferir-se a grande batalha da inteligência contra o erro, do bem contra o mal, da virtude contra o vício, da civilização contra a barbárie. ${ }^{17}$

A instalação das bibliotecas populares não seguiu um único padrão. $\mathrm{Na}$ grande maioria dos casos, sua implementação partiu da ação voluntariosa de um "benemérito das letras"18, sobretudo de membros da elite local representada por fazendeiros portadores de títulos da nobreza imperial ou de patentes da Guarda Nacional, desejosos de produzir uma memória autocelebrativa e de alçar a sua terra natal à condição de um centro de progresso e cultura. Contudo seria equivocado circunscrever este movimento à ação das elites. Ele foi adensado com a participação ativa de estratos sociais médios representados por farmacêuticos, médicos, advogados, comerciantes, professores, delegados e demais membros do funcionalismo público. Não por acaso, é deste segmento que se desencadeiam algumas formas exemplares de conduta ou atividades

${ }^{16}$ Pe. Antonio de Maria Ibiapina. "Bibliotheca Popular do Crato". A voz da religião no Cariri (Juazeiro, CE, 1870), s/p.

17 Franklin Martins. "Discurso proferido pelo Orador da Bibliotheca Popular Pesqueirense, na sua sessão de 06/05/1883”. Jornal do Recife (PE), 22/05/1883, 2.

18 A expressão é de Rubens Borba de Moraes. O problema das bibliotecas brasileiras (Rio de Janeiro: Casa do Estudante do Brasil, 1942) 37. 
visando a arrecadação de verbas, como por exemplo, a doação de uma parcela dos vencimentos por parte do administrador de rendas municipal, seguida pelo escrivão, pelo professor e por um negociante (Mossoró), a contribuição em dinheiro pelo farmacêutico e professores locais (Limeira de Itaboana), a doação realizada pelo juiz de direito (Capivari), o financiamento parcial por meio de um concerto de piano (Barra Mansa), ou ainda, a doação de estantes e mobiliário pelo vereador (Diamantina) ${ }^{19}$.

Importa ressaltar que a manutenção destas bibliotecas também se orientou por pressupostos distintos. Em alguns casos, a benevolência de seus fundadores foi acompanhada pela destinação de recursos próprios para dar suporte e perpetuidade à instituição. Esta modalidade foi evidenciada no discurso inaugural da Biblioteca Popular de São Luís, proferido pelo seu diretor, o advogado e deputado José de Almeida Oliveira, que exclamava: “...provavelmente vos tem parecido esquisito o nosso Regulamento em razão de não conter uma palavra acerca dos meios de vida da Biblioteca. É verdade: para se sustentar este estabelecimento não pedimos mensalidade, nem anuidade alguma, a quem quer que seja" ${ }^{20}$. Por sua vez, outras iniciativas estiveram assentadas naquela prática denominada por R.J. Morris de "democracia da subscrição" ${ }^{1}$, isto é, no pagamento de um título de associado e de taxas anuais, semestrais ou mensais. A contribuição financeira para a manutenção do estabelecimento não tornava excludente a sua frequentação, todavia além de conferir um status ao associado, facultava-lhe o empréstimo das obras para a leitura doméstica. O estatuto da Biblioteca Popular Pesqueirense evidenciava uma diferença entre o leitor ordinário, cujo acesso era franqueado gratuitamente, e aqueles que eram admitidos como "sócios instaladores efetivos", conforme assinalado no capítulo II, artigo 3: "Para ser sócio instalador e efetivo é preciso ser maior de

19 Respectivamente: Diário de Pernambuco (PE), 26/02/1874, 2; Gazeta de Notícias (RJ), 04/06/1876, 2; Correio Paulistano (SP), 05/02/1875), 2; A República (RJ), 20/09/1873, 1; A Nação (RJ), 04/05/1874.

${ }^{20}$ Discursos lidos na inauguração da Bibliotheca Popular Maranhense aos 19 de outubro de 1872 (Maranhão: Typ. do Paiz, 1872), 6.

${ }^{21}$ De acordo com o autor, o procedimento era o seguinte: "Money was collected from members. The funds were distributed and activities organized by a committee and officers elected by the subscribers at the annual general meeting. One subscription, one vote, was the general rule and uncontested elections the normal practice. Normally the result was ruled by an oligarchy selected from the higher status members of the society'. R.J. Morris. "Voluntary Societies and British Urban Elites, 1780-1850: An analysis". The Historical Journal, London, v.26 n.1 (1983) 101. 
quinze anos, e, sendo menor, ter diploma de exames conferido em escolas de instrução primária pública ou particulares, ter bom comportamento, meios de subsistência e estar livre de processo criminal"22. Mais adiante, explicitava que todo sócio deveria parar uma joia de cinco mil réis (cap.II, art. $8^{\circ}, \$ 1$ ) e uma mensalidade de mil réis (cap.II, art.8,$\$ 2$ ), além de ter de doar ao menos um livro para o acervo da biblioteca (cap.VII art.55을. Ainda que o estatuto mencione como finalidade última a instrução, sua redação adotava de maneira explícita a distinção entre "os sócios e o povo" (cap.I, art.1º,$\$ 1$ ). Desta maneira, acrescentava-se mais um atributo negativo ao povo, isto é, por estar desprovido de recursos para efetuar o pagamento das taxas exigidas pela instituição, se estabelecia uma analogia entre o povo/popular e o pobre/pobreza. Por sua vez, o antagonismo creditava uma aura aos associados, a saber, transferia para cada um deles um bônus simbólico, seja de uma perspectiva laica ou religiosa, de contribuir para o progresso civilizacional na qualidade de benfeitor.

Convém ressaltar, que o processo de fundação e gestão das bibliotecas instaladas na província do Rio de Janeiro seguiu caminhos distintos daquelas formas de mobilização verificadas nas demais localidades do Império. Sua especificidade repousava no fato de que, ao invés de contar com a benevolência das elites ou a filantropia dos setores médios, coube ao Estado o papel de instituir, manter e divulgar a rede de bibliotecas populares. Por meio de um ato legislativo, formalizado no decreto-lei no 1650 (1871) e promulgado pelo presidente da província, Josino do Nascimento Silva, declarava-se que:

Art. $1^{\circ}$ Fica criada em cada uma das cidades da província uma biblioteca popular;

$\$ 1$-A biblioteca se comporá principalmente de manuais e tratados práticos de artes e ofícios, agricultura, história, literatura e moral em português e das edições em menor preço.

$\$ 2$ - (...) Quer a leitura, quer o empréstimo dos livros, será inteiramente gratuito e deverá ser facilitado aos indivíduos de todas as classes e condições de que se queiram utilizar, uma vez que saibam ler. ${ }^{23}$

Salta às vistas a pretensão do governo em instalar as bibliotecas em todas as cidades da província, fato que jamais se consumou. Todavia, o texto

${ }^{22}$ Estatuto da Bibliotheca Popular Pesqueirense (Recife: Typographia Central, 1882) 5.

${ }^{23}$ Collecção de leis, decretos e regulamentos da província do Rio de Janeiro [Rio de Janeiro: Typ. da Papelaria Parisiense, 1889 (2⿺ ed)], 181. As bibliotecas populares implantadas na província do Rio de Janeiro estão arroladas no Quadro 1. 
normativo indicava com precisão o perfil do acervo preconizado pelos gestores, sintonizado com o projeto de proporcionar instrução e deleite para as classes populares. A predileção pelo vernáculo, a delimitação temática e a opção pelas "edições baratas" ajudam a prefigurar o tipo de leitor que frequentaria a biblioteca, bem como, transferia algumas qualidades e sentidos para aquilo que se daria a ler. Por se tratar de uma política pública destinada a facilitar o acesso ao livro e difundir o hábito da leitura, é fundamental destacar a positividade indicada no corpo da lei que visava garantir a livre circulação dos leitores, a gratuidade e o empréstimo para a leitura doméstica.

Ainda conforme previa a norma jurídica, estas bibliotecas ficariam submetidas ao poder administrativo das câmaras municipais, que deveriam ceder espaço físico para a sua instalação e arcar com os salários dos funcionários e com os custos do consumo de gás destinado à iluminação. Em contrapartida, o governo provincial se comprometia a dispender "até 300 mil réis com o preparo da sala de cada uma das bibliotecas e até 500 mil réis com cada uma das bibliotecas e até 500 mil réis com cada uma para fornecimento dos primeiros livros. Cada biblioteca terá uma subvenção anual de 300 mil réis para a compra de novos livros e a conservação dos já existentes" 24 .

Diferentemente das práticas assistemáticas de controle do acervo e do registro do movimento de leitores verificadas em grande parte das bibliotecas populares, a legislação fluminense determinava ao funcionário público que se encontrava investido no cargo de bibliotecário, a preparação anual de um relatório pormenorizado. Nele deveria constar o movimento de leitores, as obras extraviadas, os títulos mais solicitados e as novas obras desejadas pelos leitores. No entanto, os informes enviados ao Diretor da Instrução Pública, responsável por recolher e condensar estas informações, revelam que a recomendação era na maioria das vezes desrespeitada e que os dados coligidos apresentavam lacunas.

O fato é que os indicadores divulgados nos relatórios apontavam uma inequívoca lentidão na instituição da rede de bibliotecas populares. Como se isto não fosse suficiente, alguns relatórios são enfáticos ao designarem as bibliotecas populares como "ornato" ou "cemitério de livros", em grande medida demonstrando uma paradoxal discrepância entre o perfil do acervo e as prescrições previstas na lei. Conforme registrou o inspetor da instrução pública:

${ }^{24}$ Cf. "Collecção de leis”, 182. 
"Muito timidamente, aventurarei uma observação: as bibliotecas populares como estão estabelecidas, não preenchem o fim de sua criação, nem podem preencher. Romances, romances e muitos romances. Poucos livros técnicos, escritos para elas, destinados a propagar pelo povo os descobrimentos científicos e os melhores processos industriais. Quererei muito? Estarei fora do assunto? É o programa de Jules Simon para as bibliotecas populares, e Jules Simon é autoridade reconhecida." ${ }^{25}$

O excerto do relatório além de reiterar a assimetria entre o projeto e sua concretização, mencionava a matriz política e cultural que inspirou a experiência fluminense. Diferentemente da matriz frankliana, exaltada e mencionada pelos fundadores das bibliotecas populares nas demais províncias, de caráter comunitário, autonomista e ancorada na religião civil do livro e da leitura, o projeto implementado no Rio de Janeiro parecia estar mais identificado com os debates e pressupostos políticos franceses que, em última instância, enxergavam a "leitura pública" como um dever do Estado ${ }^{26}$. Por isso mesmo, não causa estranheza a menção à Jules Simon, Ministro da Instrução Pública na França (1870-1873), que desempenhou um papel fundamental na regulamentação das bibliotecas populares e comunitárias por parte do Estado. Seu ensaio "L'Instruction primaire et les Bibliothèques populaires en France"27, publicado na Revue des Deux Mondes, periódico de ampla circulação no Brasil

${ }^{25}$ Relatório da Instrucção Publica. En: Relatório apresentado a Assembleia Legislativa Provincial do Rio de Janeiro (Rio de Janeiro: Typ. do Apóstolo, 1875) S3-41.

${ }^{26}$ Para compreensão da experiência norte-americana e o modelo inspirado em Benjamin Franklin, veja: Jean Hassenforder. Développement comparé des bibliothèques publiques en France, en Grande-Bretagne et aux Etat-Unis dans la seconde moitié du XIXe siècle (1850-1914) (Paris: Cercle de la librairie, 1967); Thomas Augst and Kenneth Carpenter (ed.s). Institutions of Reading (Amherst and Boston: University of Massachusetts Press, 2007). Já, para a experiência francêsa, veja: Martyn Lyons. Le triomphe du livre (Paris: Promodis, 1987), especialmente 177-196; Noë Richter. "Les bibliothèques populares et la lecture ouvrière". En: Histoire des bibliothèques françaises. v.3., dirigido por Dominique Varry (Paris: Cercle de la Librairie/Promodis, 1991).

27 Jules Simon. "L'Instruction primaire et les Bibliothèques populaires en France". Revue des Deux Mondes, 2e période, tome 47 (1863): 349-375. Sobre a circulação e recepção da Revue des Deux Mondes no Brasil, veja: Katia Aily Franco Camargo. A Revue des Deux Mondes intermediária entre dois mundos (Natal: Ed.UFRN, 2007); Eliana de Freitas Dutra. "The Revue des Deux Mondes in the context of transatlantic exchanges". En: The Cultural Revolution of the Nineteenth Century: Theatre, the Book Trade, and Reading in the Transatlantic World, organizado por Márcia Abreu e Ana Claudia Suriane Silva (London/New York: Tauris\& Co., 2016) 121138. 
imperial, também foi objeto de menção no debate parlamentar sobre a reforma da instrução e a implantação das bibliotecas populares no Rio de Janeiro.

A despeito do otimismo em relação ao processo de instalação de bibliotecas populares e de tentar satisfazer as demandas da instrução popular, a experiência fluminense foi alvo de preocupações e críticas furibundas por parte de vários deputados. Dentre eles, Theodureto Carlos de Faria Souto posicionava-se contra o "zelo centralizador do governo" nos seguintes termos:

O que o regulamento dispõe sobre as bibliotecas populares é em detrimento da iniciativa e da expansão das forças locais. Toda a biblioteca que se erigir na província, ainda que seja à custa de sacrifícios particulares, se invocar o auxílio da administração, se dela receber um ceitil de subsídio retirado desta verba, aliás bem parca e modesta do orçamento, e destinada a subvencionar essas instituições, cai desde logo sob a jurisdição do governo, e está sujeita à inspeção, fiscalização e vexames de toda a sorte inerente à intervenção administrativa. ${ }^{28}$

Sua exasperação, assentada em um argumento fortemente impregnado por referências liberais, considerava a "intervenção administrativa" nas práticas comunitárias que forjaram as bibliotecas e a instrução decorrente da implantação dos cursos noturnos, como uma usurpação da iniciativa popular. E continuava o seu discurso, nos seguintes termos:

(...) o governo só quer invadir todos os âmbitos da atividade social; é a insânia de arregimentar, de unificar, de absorver: é a demência da autocracia centralizadora, que se torna ridícula quando desce a regentar atos da vida doméstica das populações livres, que nada mais desejam do que operarem os desenvolvimentos espontâneos das suas faculdades dentro do seu território...

Eu sei que os governos despóticos têm medo da leitura, ela é rica de inspirações (...) Montesquieu dizia que não há tristeza que resista a meia hora de leitura atenta; e é bom não deixar o espírito do povo tomar-se de tristeza, entrar dessa melancolia negra, que é a causa de revoluções. Veja V.Exa. que até por esse lado as bibliotecas se afiguram como instrumentos do governo" 29 .

\footnotetext{
${ }^{28}$ Debates da sessão legislativa de 03 a 06/02/1877. Jornal do Commercio (RJ), 01/04/1877, 3 .

${ }^{29}$ Jornal do Commercio, 3.
} 
Apesar da relutância em admitir o papel diretivo e centralizador do poder público e das formas de controle advindas do repasse de verbas, a prática de subsidiar as bibliotecas populares não foi uma prerrogativa do governo do Rio de Janeiro, mas foi amplamente empregada nas demais províncias, sob a forma de loterias e atos do executivo. $\mathrm{O}$ que se tornou peculiar no plano adotado no Rio de Janeiro foi o fato de que as bibliotecas populares passaram a ser incorporadas enquanto dispositivo formal para a instrução. E, como tal, deveriam submeter-se aos sistemas hierarquizados de administração e controle do Estado. Portanto, para além do apelo autonomista, é preciso reconhecer que o auxílio decorrente da ação política centralista garantiu a sobrevida de muitas delas.

Entretanto, seria equivocado limitar o processo de implantação das bibliotecas populares no Brasil oitocentista às duas perspectivas destacadas até o momento, isto é, a daquelas capitaneadas pela ação generosa de indivíduos e a que resulta de diretriz política levada a cabo pelo governo fluminense. Tratase, pois, de apresentar uma terceira via. A sondagem da imprensa indicou a existência de estabelecimentos, cuja gênese esteve alicerçada na atuação de associações voluntárias representadas por lojas maçônicas, clubes republicanos e abolicionistas, e de várias entidades envolvidas nas questões da instrução popular.

O quadro abaixo contabiliza na ordem cronológica, o estabelecimento de bibliotecas populares fundadas por lojas maçônicas (Figura 3).

Figura 3. Bibliotecas Populares fundadas por Lojas Maçônicas

\begin{tabular}{|l|c|c|}
\hline \multicolumn{1}{|c|}{ Cidade/Província/Ano } & Loja & Filiação \\
\hline Vassouras (RJ), 1872 & Estrela do Norte & Grande Oriente do Brasil \\
\hline Amparo (SP), 1873 & Trabalho & Grande Oriente Unido \\
\hline Taubaté (SP), 1874 & Fraternidade & Grande Oriente do Brasil \\
\hline Diamantina (MG), 1874 & Atalaia do Norte & Grande Oriente Unido \\
\hline Belém (PA), 1875 & Harmonia & Grande Oriente do Brasil \\
\hline Cantagalo (RJ), 1875 & Ceres & Grande Oriente do Brasil \\
\hline Pelotas (RS), 1875 & Artista & Grande Oriente do Brasil \\
\hline Itapetininga (SP), 1876 & Cosmopolita II & Grande Oriente Unido \\
\hline Nova Friburgo (RJ), 1876 & América & Grande Oriente Unido \\
\hline São Paulo (SP), 1877 & Fraternidade e Progresso & Grande Oriente do Brasil \\
\hline Goiana (PE), 1878 & Lealdade e Perseverança & Grande Oriente do Brasil \\
\hline Paraíba do Norte (PB), 1884 & Lealdade e Brio & Grande Oriente do Brasil \\
\hline Rezende (RJ), 1884 & Estrela do Oriente & Grande Oriente do Brasil \\
\hline S. Carlos do Pinhal (SP), 1884
\end{tabular}

Fuente: elaboración propia. 
As iniciativas que partiram de lojas maçônicas resultaram na implantação de 14 bibliotecas populares distribuídas por 6 províncias, perfazendo cerca de $20 \%$ do total de instituições congêneres estabelecidas no Império. No entanto, esta cifra camufla uma clivagem entre as frações da maçonaria, que resultam de orientações políticas distintas. Enquanto as nove lojas filiadas ao Grande Oriente Brasil adotavam tendências majoritariamente monárquicas e conservadoras, aquelas cinco ligadas ao Grande Oriente Unido expressavam orientações republicanas e positivistas. Milena Candiá considerou estas ações "isoladas e efêmeras" quando confrontadas com outras iniciativas mais ousadas e perenes, sobretudo "aqueles projetos que extrapolaram os limites da Ordem, tendo sua fundamentação e apoio de uma parcela da sociedade profana" ${ }^{\text {" }}$, cujo resultado proporcionou fins e meios mais incisivos para a questão da instrução popular. Ainda de acordo com a pesquisadora, as bibliotecas populares e as aulas noturnas para os trabalhadores fizeram parte de uma intervenção que se desdobrou, muitas vezes, na "criação de escolas que ofereciam o ensino primário e secundário gratuitos, organizando conferências, fundando revistas e jornais de caráter pedagógico ou político"31. De qualquer maneira, importa sublinhar que a instituição de bibliotecas populares se articulava com o ativismo de grupos maçons em prol da educação livre da autoridade governamental, do ensino laico e científico, e das ações voltadas para o "melhoramento e progresso" das classes populares.

Para além do ativismo dos grupos maçons, mas ainda assim contando muitas vezes com a presença de seus membros, e adotando valores identificados com esta ordem, foi possível identificar outras 15 associações voluntárias, que representam cerca de $22 \%$ do total de instituições levantadas, conforme quadro abaixo (Figura 4).

${ }^{30}$ Milena Aparecida Almeida Candiá. Projetos e realizações culturais e pedagóógicas maçônicas: 0 associativismo como terceira via para (re)pensar a educação popular no Brasil-Império (18701889). Niterói: Universidade Federal Fluminense, 2013 (Doutorado em Educação), 136. Ainda sobre a Maçonaria no Brasil, veja: Michel Silva (org.). Maçonaria no Brasil: história, política e sociabilidade (Juandiaí: Paco Editorial, 2015).

${ }^{31}$ Michel Silva, "Maçonaria no Brasil”, 161. 
Figura 4. Bibliotecas fundadas por associações voluntárias

\begin{tabular}{|l|c|}
\hline Cidade/Província/Ano & Associação \\
\hline Paranaguá (PR), 1872 & Club Literário \\
\hline Ubá (MG), 1874 & Sociedade Protetora da Instrução \\
\hline Teresina (PI), 1874 & Sociedade Protetora da Instrução \\
\hline Porto de Cima (PR), 1874 & Sociedade Protetora da Instrução \\
\hline Laguna (SC), 1875 & Grêmio de Instrução Popular \\
\hline São Luís (MA), 1878 & Grêmio dos Professores Primários \\
\hline Recife (PE), 1878 & Sociedade Propagadora da Instrução \\
\hline Recife (PE), 1878 & Grêmio de Instrução Popular \\
\hline Recife (PE), 1878 & Sociedade Propagadora da Instrução Pública \\
\hline Monteiro (PE), 1879 & Sociedade Propagadora da Instrução Pública \\
\hline Recife (PE), 1879 & Club Literário \\
\hline Bragança Paulista (SP), 1882 & Grêmio Democrático Literário \\
\hline Limeira (SP), 1887 & Sociedade Comemorativa 13 de Maio \\
\hline Jundiaí (SP), 1888 & União Republicana \\
\hline Pelotas (RS), 1889 &
\end{tabular}

Fuente: elaboración propia.

A listagem é majoritariamente composta por associações devotadas à causa da instrução e abrange capitais e cidades do interior de 5 províncias. As bibliotecas populares funcionavam aqui como mais um dos dispositivos empregados na reversão do analfabetismo, na qualificação dos trabalhadores e como suporte para as aulas noturnas e formação de professoras. A concentração verificada na província de Pernambuco traduzia a capacidade organizativa bem-sucedida por parte da Sociedade Propagadora da Instrução Pública. O rol das bibliotecas instituídas sob a ação e cultura associativa desta Sociedade demonstra também sua atuação em outros pontos do Império ${ }^{32}$. A presença de bibliotecas populares no seio de clubes literários e associações identificadas com o ideário republicano e abolicionista não causa espanto. Pelo contrário, elas foram concebidas como um espaço de sociabilidade para forjar, por meio da leitura, um novo cidadão e, consequentemente, contribuir para

32 Para a compreensão mais pormenorizada da atuação de algumas destas associações, veja: Daniel Cavalcanti de Albuquerque Lemos. Professores em movimento: A Emergência do associativismo docente na Corte Imperial. Belo Horizonte: Universidade Federal de Minas Gerais, 2011 (Doutorado em Educação); Milena Aparecida Almeida Candiá, "Projetos e realizações culturais”; Yan Soares Santos. A Sociedade Propagadora da Instrução Pública e suas ações de Qualificação Profissional em Recife (1872-1903). Recife: Universidade Federal de Pernambuco, 2014 (Mestrado em Educação). 
o "aperfeiçoamento intelectual e moral da sociedade". Portanto, apesar da variedade de propósitos, observa-se uma convergência entre as associações voluntárias arroladas.

A nota dissonante é representada pelo Clube Literário, fundado por escravos na cidade de Bragança Paulista. Ao largo das ações encabeçadas pelas elites e pelos setores médios, esta iniciativa demonstra a capacidade de autoorganização dos escravos e a busca de estratégias já consagradas para acessar os potenciais benefícios da cultura letrada. Especialmente em um momento em que o abolicionismo deixa de ser um apanágio de partidos e instituições políticas, o associativismo dos escravos e a criação de uma biblioteca popular poderia contribuir para concretizar os sonhos de liberdade.

O apelo por doações de livros e periódicos para a biblioteca popular do Clube Literário dirigido por escravos, na cidade de Bragança Paulista, suscitou reações adversas. Foi objeto de sarcasmo e de censura por parte dos redatores do jornal de Pitangui (MG) que não poupou palavras para aviltar aquela experiência formativa, nos seguintes termos: "O presidente é um escravo, e escravo é também o secretário e tudo mais. Ora os escravos metidos em letras! $\mathrm{O}$ progresso não tem limites. Que perniciosas propagandas hão de sair desse club!"33. Na mão contrária, os proprietários do diário liberal bonaerense A Pátria Argentina, "os srs. Dr.s Ricardo Gutierrez e João Gutierrez, não só acederam o pedido da remessa do seu diário, como efetuaram uma oferta de livros para o Club e a soma de quarenta pesos para a ajuda das despesas de sua instalação" ${ }^{34}$, demonstrando uma recepção positiva em relação aos propósitos deste clube e, de maneira mais ampla, assumindo o papel de divulgação da causa abolicionista fora do Brasil.

De maneira distinta do perfil de outras bases institucionais de leitura no Brasil oitocentista, cujos quadros diretivos e associativos eram marcados por um forte componente misógino, foi possível constar a presença e a participação feminina em muitas bibliotecas populares. A inclusão de gênero se manifestou de distintas maneiras. As mulheres adentraram na vida cultural e política das bibliotecas populares muitas vezes de forma coadjuvante, isto é, de braço dado com o marido, pai ou irmão. Sobretudo nas efemérides, a presença feminina foi objeto de destaque por parte da imprensa.

${ }^{33}$ O Iniciador (Pitanguy, MG), 09/04/1882, 1.

34 "Club Litterário de Escravos". Jornal do Recife (Recife, PE), 08/09/1882, 1, que reproduz informação publicada no Correio de Portugal, periódico português de Montevidéo. 
Contudo, outras formas mais ativas de participação das mulheres também foram detectadas. Dentre elas, a filantropia caracterizou a via canônica. A sociedade escravocrata liberava as senhoras de alta extração do serviço doméstico, proporcionando tempo livre para se dedicar a causas cristãs e beneméritas. Por isso mesmo, algumas figuram como partícipes ativas nas cerimônias públicas, quando não, atuando no campo educacional, conforme as palavras proferidas por Leovegilda Ferraz, por ocasião da inauguração da Biblioteca Popular de Cantagalo:

“(...) Já não somos unicamente a flama sempre viva do amor, somos também um raio brilhante de ideia.

Conquistamos um posto junto à bandeira da vanguarda, onde marcham os que sacodem o facho da ilustração a alumiar a vereda imensa do progresso. Sim, meus senhores, a mulher no século dezenove, exerce também o magistério. Eque magistério!

(...) Eis aí uma missão que já é nossa. Eis aí um apostolado, que começamos. Nós também queremos concorrer para a obra de instrução popular, nós que já somos os principais agentes da educação social.

O que é uma biblioteca?

É uma escola, como o jornal, como o teatro, como a conferência, como o liceu, como a academia. Dai-nos um lugar nessa escola para ensinar, para aprender, ou antes, para aprender e depois ensinar. ${ }^{.35}$

A crer nos discursos salvacionistas associados à função das bibliotecas havia também uma preocupação bastante evidente de fazer com que os livros chegassem às mãos das leitoras. Portanto, a instalação de bibliotecas populares também representou um novo padrão de sociabilidade, franqueando ao público feminino uma autonomia relativa para incursões no mundo extra doméstico. Por isso mesmo era necessário estabelecer critérios e recomendações sobre aquilo que seria oferecido ao "belo sexo". Não raro, era prescrito às leitoras o contato com livros de conteúdos moralizantes ou que despertassem "o amor ao trabalho, à moral, à religião, à economia, às mais importantes verdades sociais, à higiene, à fisiologia, deve ser requisito indispensável da instrução e educação de todas ${ }^{36}$. Se existiam livros que se adequavam às representações sobre o lugar e a

35 "Discurso proferido pela Exma. Sra. Leovegilda Ferraz na inauguração da Bibliotheca Popular de Cantagallo". O Globo (RJ), 20/05/1875, 3.

${ }^{36}$ Discursos lidos na inauguração da Bibliotheca Popular Maranhense aos 19 de outubro de 1872 (Maranhão: Typ. do Paiz Imp. Por M.F.V. Pires, 1872). 
função das mulheres na sociedade patriarcal, constatou-se a circulação massiva de recomendações condenando a leitura de romances e todo tipo de literatura "frívola" que provocasse devaneios e estimulasse o uso da imaginação. Não raro, em resposta aos preceitos de ordem moral associados à leitura feminina foi a prática da tutela de maridos, pais e irmãos que selecionavam os títulos destinados à leitura doméstica.

Resta sublinhar que um grande problema comum enfrentado pelos gestores das bibliotecas populares dizia respeito à manutenção dos equipamentos. Como a grande maioria delas não dispunha de sede própria, tiveram uma existência errática. Submetidas a sucessivos deslocamentos, as bibliotecas populares ficaram na dependência e solidariedade dos proprietários dos imóveis ou do poder público municipal. Basta recordar que residências particulares, salas de escritório de advocacia, quartos de hotel, dependências de teatros e templos, assim como espaços comerciais foram empregados na instalação destas instituições. Da mesma forma, constatou-se uma proliferação de queixumes sobre os atrasos frequentes no pagamento das taxas por parte dos associados, os efeitos das descontinuidades administrativas e das rivalidades políticas entre os membros das câmaras municipais, o que implicava no corte de subsídios, na recusa em ceder funcionários para as atividades ordinárias como a escrituração e elaboração dos relatórios, ou ainda o não pagamento da conta de gás empregado na iluminação das salas de leitura.

O resultado alcançado pelas Bibliotecas Populares parece ter ficado muito aquém do desejo dos grupos que legislavam e administravam estas instituições porque na maioria das vezes o repertório dos livros alocados nas estantes não se adequava aos protocolos forjados para a instrução popular. O longo argumento empregado pelo Inspetor Geral da Instrução da Província do Rio de Janeiro, em 1881, explicita uma série de paradoxos.

As bibliotecas populares estão muito longe de corresponder por sua composição ao seu fim natural - à instrução do povo - não à instrução profunda ou sistemática, por impossível, mas a de acumulação de conhecimentos aplicáveis aos usos da vida.

Compostas todas ou de livros de alta ciência, e por isso incompatíveis com os intuitos da instituição, ou de romances de imaginação ou de costumes, cuja leitura poderá distrair, mas nunca ilustrar o espírito, nem desenvolver o senso prático, estão na maior parte condenadas pelos instintos populares, de sorte que a sua frequência é relativamente insignificante. 
Que utilidade poderá prestar ao povo a biblioteca de Nova Friburgo, composta em grande parte de obras de alto valor científico, mas inacessíveis à compreensão? Ou a de Macaé na sua maioria provida de livros de direito e de prática forense? Ou a de Itaboraí, amálgama de obras difíceis de ciência, romances, legislação e relatórios? Ou a maçônica de Cantagalo, onde existem, é verdade, alguns trabalhos sobre artes e indústria, mas tudo em francês? ${ }^{37}$

O arrolamento destes sucessivos paradoxos entre aquilo que se dava a ler e o caráter pragmático previsto no funcionamento das bibliotecas populares mostra o quanto era difícil satisfazer as finalidades previstas em seus estatutos e acatar o arcabouço jurídico que sancionava a instalação desta rede de instituições. Diante das remessas descontínuas de recursos para aquisição de livros, da ausência de isenção de taxas para a importação de coleções que pudessem satisfazer as diretrizes legais das bibliotecas populares, da incapacidade do mercado nacional em suprir a carências de títulos e repertório, os acervos se expandiram com base no descarte de bibliotecas privadas de letrados locais, de publicações oficiais enviadas pelas repartições públicas provinciais e imperiais. Para decepção de padres, professores, bacharéis e políticos, as "obras úteis" foram suplantadas pelas obras literárias, e dentro desta categoria, o gênero triunfante foi o romance, que ocupava invariavelmente a primeira posição entre as classes de livros mais bem servidas nos acervos e também entre os mais solicitados pelos leitores. Sendo assim, parece ser bastante plausível a hesitação e a asserção do encarregado de aferir o funcionamento da rede de bibliotecas populares implantadas na província do Rio de Janeiro quando afirmava:

Alguém, dando-me informação da biblioteca do seu município, escreveu esta frase ou outra equivalente: "Os romances que vieram já foram lidos todos, mande-nos outros". Querer derramar a instrução pela leitura de romances é imperdoável. O ledor dessas composições habitua-se a elas, perverte o espírito, e inabilita-se para a leitura séria, única que pode ser proveitosa ao povo. Digo-o por experiência própria: fui e talvez seja ainda (é mau hábito que não se perde) apaixonado por essa leitura; e quantas vezes não tenho preterido verdadeiras obrigações por ela! É confissão íntima: faço-a para fundamentar a competência do meu juízo. ${ }^{38}$

${ }^{37}$ Relatório apresentado à Assembléa Legislativa Provincial do Rio de Janeiro na abertura da 23a legislatura em 08 de agosto de 1881 pelo presidente Dr. Martinho Álvares da Silva Campos (Rio de Janeiro: Imp. Ind. de João Paulo Ferreira Dias, 1881) 43.

${ }^{38}$ Exposição com que o Cons. Francisco Xavier Pinto Lima (Rio de Janeiro: s/e, 1877) 22-23. 
Os muitos desencontros e desajustes arrolados aqui, ajudam a entender a crise que atingiu o movimento em prol das bibliotecas populares. $\mathrm{O}$ artigo referente ao encerramento das atividades da Biblioteca Pública da Paraíba no Norte (PB) é um pungente desabafo e dá mostras do desencanto que abateu a experiência local.

Não é porventura uma instituição de tanta utilidade a biblioteca? (...) Haverá meio mais fácil para levar o lume da instrução até as últimas camadas sociais, de derramar como um batismo santo as águas lustrais da ciência sobre a promíscua cabeça do povo - essa eterna criança sedenta de luz e saber?

A Biblioteca Popular desta cidade não proporcionava leitura agradável e variada, gratuitamente, aos que a frequentavam, e pelo mais módico preço aos seus assinantes?

Entretanto foi forçoso que ela se fechasse, porque o público deixou de prestar-lhe a coadjuvação necessária para manter-se. Ela funcionou regularmente por cerca de quatro anos sem progresso sensível, porque partindo de poucos, era fraco o apoio, de que gozava. O período de existência funcional não foi bastante para criar o gosto e acostumar o povo, de modo a reputa-la uma necessidade da qual não quisesse ver-se privado. $^{39}$

Não parece equivocado afirmar que entre os anos 1870 e 1889 , o projeto de implantação de bibliotecas populares no império brasileiro experimentou um percurso que poderia ser emblematizado pelo título de dois romances bastante lidos naquele período. Elas viveram "grandes esperanças" e, posteriormente, mergulharam em irreversíveis "ilusões perdidas". Aabolição tardia da escravidão em 1888, a ascensão da ordem republicana em 1889 e o grande fluxo de imigrantes colocaram novos desafios para a integração do "povo" e a formulação de novas estratégias para a instrução e leitura.

${ }^{39}$ Gazeta da Paraíba (PB), 21/12/1889, 1. 


\section{Referencias bibliográficas}

\section{Fuentes primarias}

\section{Impresas}

A Nação (RJ)

A República (RJ)

Correio do Assú (Assú, RN)

Correio Paulistano (SP)

Diário de Notícias (RJ)

Diário de Pernambuco (PE)

Gazeta da Paraíba (PB)

Gazeta de Notícias (RJ)

Jornal do Commercio (RJ)

Jornal do Recife (PE)

Jornal do Recife (Recife, PE)

O Globo (RJ)

O Iniciador (Pitanguy, MG)

O Mosquito (RJ)

O Movimento (RJ)

\section{Fuentes secundarias}

Alberto Rebelo, Carlos. A difusão da leitura pública: As bibliotecas populares (18701910). Porto: Campo das Letras, 2002.

Alonso, Angela. "Associativismo avant la lettre - as sociedades pela abolição da escravidão no Brasil oitocentista”. Sociologias ano 13, nํ28, set./dez (2011).

Alves, Castro. Obra Completa. Rio de Janeiro: Nova Aguilar, 1976.

Aparecida Almeida Candiá, Milena. Projetos e realizações culturais e pedagógicas maçônicas: o associativismo como terceira via para (re)pensar a educação popular no Brasil-Império (1870-1889). Niterói: Universidade Federal Fluminense, 2013 (Doutorado em Educação).

Augst, Thomas e Kenneth Carpenter (ed.s). Institutions of Reading: The social life of Libraries in the United States. Amherst and Boston: University of Massachusetts Press, 2007.

Barthes, Roland. Da leitura. O rumor da língua. São Paulo: Brasiliense, 1988.

Bocayuva, Quintino. Estudos criticos e literários. Rio de Janeiro: Typographia $\mathrm{Na}-$ cional, 1858.

Cavalcanti de Albuquerque Lemos, Daniel. Professores em movimento: A Emergência do associativismo docente na Corte Imperial. Belo Horizonte: Universidade Federal de Minas Gerais, 2011 (Doutorado em Educação).

Chartier, Anne-Marie e Jean Hébrard. Discours sur la lecture (1880-1980). Paris: Centre Georges Pompidou, 1989.

Collecção de leis, decretos e regulamentos da província do Rio de Janeiro. Rio de Janeiro: Typ. da Papelaria Parisiense, 1889 (2 $\left.{ }^{\mathrm{a}} \mathrm{ed}\right)$. 
Compagnon, Antoine. O trabalho da citação. Belo Horizonte: Ed.UFMG, 1996.

De Assis, Machado. “História de Quinze Dias (15/08/1876)”. En: Obra Completa v.III. Rio de Janeiro: Nova Aguillar, 1986.

De Freitas Dutra, Eliana. "The Revue des Deux Mondes in the context of transatlantic exchanges". En: The Cultural Revolution of the Nineteenth Century: Theatre, the Book Trade, and Reading in the Transatlantic World, organizado por Márcia Abreu e Ana Claudia Suriane Silva. London/New York: Tauris\& Co., 2016.

De Maria Ibiapina, Pe. Antonio. "Bibliotheca Popular do Crato". A voz da religião no Cariri. Juazeiro: CE, 1870.

De Moraes, Borba. O problema das bibliotecas brasileiras. Rio de Janeiro: Casa do Estudante do Brasil, 1942.

Denipote, Cláudio. "Decência imperial, silêncio republicano: normas e gestualidades da leitura em regimentos e estatutos de bibliotecas (1821-1918)”. Varia História v. 23 nํ38 (2007) 597-614.

Discursos lidos na inauguração da Bibliotheca Popular Maranhense aos 19 de outubro de 1872. Maranhão: Typ. do Paiz, 1872.

Estatuto da Bibliotheca Popular Pesqueirense. Recife: Typographia Central, 1882.

Exposição com que o Cons. Francisco Xavier Pinto Lima. Rio de Janeiro: s/e, 1877.

Franco Camargo, Katia Aily. A Revue des Deux Mondes intermediária entre dois mundos. Natal: Ed.UFRN, 2007.

Frota Martinez, Alessandra. Educar e Instruir: A Instrução Popular na Corte - 1870 a 1889. Niterói: Universidade Federal Fluminense, 1997.

García Ejarque, Luis. Historia de la lectura pública em España. Gijón: Trea, 2000.

Hallewell, Laurence. O livro no Brasil. 2. ed. revista e ampliada. São Paulo: Edusp, 2005.

Hassenforder, Jean. Développement comparé des bibliothèques publiques en France, en Grande-Bretagne et aux Etat-Unis dans la seconde moitié du XIXe siècle (1850-1914). Paris: Cercle de la librairie, 1967.

Keith Barnett, Grahan. Histoire des bibliothèques publiques en France de la Révolution à 1939. Paris: Cercle de la Librairie/Promodis, 1987.

Lamenha Lins, Adolpho. Relatorio apresentado á Assembléa Legislativa do Paraná no dia 15 de fevereiro de 1877 pelo presidente da provincia. Curityba: Typ. da Viuva Lopes, 1877.

Lyons, Martyn. Le triomphe du livre. Paris: Promodis, 1987.

Machado Martins Pinto, Maria de Fátima. Bibliotecas Populares em Portugal: Práticas e representações, esboçar uma missão (1870-1930). Lisboa: Instituto de Educação/ Universidade de Lisboa, 2017 (Tese de doutorado).

Mendes Faria Filho, Luciano. "Educação do povo e autoritarismo das elites: instrução pública e cultura política no século XIX". Dimensões. Vitória, v.13 (2001): 75-83.

Morris, R.J. "Voluntary Societies and British Urban Elites, 1780-1850: An analysis". The Historical Journal, London, v.26 n.1 (1983).

Petrucci, Armando. “Bibliotecas y lectura: entre progresso y conservación”. En: Alfabetismo, escritura, sociedade. Barcelona: Gedisa, 1999. 
Planas, Javier. Libros, lectores y sociabilidades de lecturas: Una historia de los orígenes de las bibliotecas populares en la Argentina. Buenos Aires: Ampersand, 2017.

Quiroga, Nicolás. "Lectura y política. Los lectores de la Biblioteca Popular Juventud Moderna de Mar del Plata (fines de los años treinta y principio de los cuarenta)". Anuario IEHS, no18 (2003): 449-474.

Relatório apresentado à Assembléa Legislativa Provincial do Rio de Janeiro na abertura da 23ํㅡㄹislatura em 08 de agosto de 1881 pelo presidente Dr. Martinho Álvares da Silva Campos. Rio de Janeiro: Imp. Ind. de João Paulo Ferreira Dias, 1881.

Relatório apresentado a Assembleia Legislativa Provincial do Rio de Janeiro. Rio de Janeiro: Typ. do Apóstolo, 1875.

Richter, Noë. "Les bibliothèques populares et la lecture ouvrière”. En: Histoire des bibliothèques françaises. v.3, dirigido por Dominique Varry. Paris: Cercle de la Librairie/Promodis, 1991.

Richter, Noë. La lecture et ses instituitions, 1700-1918. v.2. Bassac: Ed. Plein Chant et Université du Maine, 1987.

Schapochnik, N. "A leitura no espaço e o espaço da leitura”. Cultura letrada no Brasil: objetos e práticas, organizado por Márcia Abreu e Nelson Schapochnik. Campinas/ São Paulo: Mercado de Letras/FAPESP, 2005.

Silva, Michel (org.). Maçonaria no Brasil: história, política e sociabilidade. Juandiaí: Paco Editorial, 2015.

Simon, Jules. "L'Instruction primaire et les Bibliothèques populaires en France". Revue des Deux Mondes, 2e période, tome 47 (1863): 349-375.

Soares Santos, Yan. A Sociedade Propagadora da Instrução Pública e suas ações de Qualificação Profissional em Recife (1872-1903). Recife: Universidade Federal de Pernambuco, 2014 (Mestrado em Educação).

Viñao Frago, Antonio. "A cultura por la lectura. Las Bibliotecas populares (18691885)”. En: Clases populares, cultura, educación, siglos XIX-XX, editado por JeanLouis Guereña y Alejandro Tina. Madrid: Casa de Velázquez/UNED, 1989. 